\title{
Analysis and Research on Teaching Methods of Advanced Manufacturing Technology
}

\author{
Zhe Wang ${ }^{1, a^{*}}$ \\ Xi'an Aeronautical Polytechnic Institute. \\ No.500, Yingbin Avenue, Yanliang District, Xi 'an City, Shaanxi Province, China. \\ a604961630@qq.com
}

\section{Key word: Advanced Manufacturing Technology; Teaching Method}

\begin{abstract}
Advanced manufacturing technology is an important professional course for students in higher vocational education to understand the frontier knowledge of manufacturing industry. This paper summarizes and analyzes the characteristics of the advanced manufacturing technology course in higher vocational colleges and the existing problems in the teaching process. In order to improve students' learning initiative, the improvement of teaching content, teaching mode, teaching means and examination process will help to improve the teaching effect.
\end{abstract}

\section{Introduction}

Higher vocational colleges are the platform for training high level skilled talents. The purpose of opening advanced manufacturing technology is to train students' operational capacity and transfer the new direction and new trends of the development of manufacturing industry at the same time. Still another is to improve the basic quality of students' professional and expand the scope of employment. However, under the effective of the traditional education pattern for a long time, the teacher release procedure, and the student accept passively, which leading to the lack of the understanding, strengthening, storage stage, the interaction between teachers and students are more absurd. According to the actual teaching experience, the paper put forward a number of measures to improve the problems existing in the current teaching process, so that the students can really benefit from this course.

\section{Teaching Characteristics of Advanced Manufacturing}

Advanced manufacturing technology is a basic course of mechanical related major in engineering colleges and universities. It focuses on the basic concept of advanced manufacturing technology, and explains modern design technology, advanced manufacturing technology and advanced production management technology from the aspects of theoretical analysis, process route, processing technology and production management mode[1]. This course covers many disciplines, such as mechanical engineering, electronic information, modern communication, materials and energy, management and so on. It has a wide and complex content, and it is constantly updated with the development of science and technology.

\section{Problems Existing in the Present Teaching Process}

Nowadays, problems existing in the present teaching process of advanced manufacturing technology are listed as follows.

The teaching mode is single. As a diversified course involves the subject of mechanical, electronic, material and management. The teaching method is mainly based on Teachers' instillation and imparting, focusing on the logic and convenience of the teaching process, and the lack of interaction between teachers and students. While the students can only learn passively according to the program designed by teachers.

The content of the textbook is lagging behind. With the development of science and technology, manufacturing technology is constantly updated and iterated. So, the development 
direction of advanced manufacturing is becoming intelligential and digitalization. The content of textbooks is lagging behind the theory proposed stage of the widely applied technology, due to the writing and publishing period of the textbooks are long and the time span is large.

The content of practical teaching is scarce. The course of advanced manufacturing technology is mainly the introduction of the present situation of the development of manufacturing technology and the knowledge points of the trend. Because of little practice and experimental operation, the students only remain in the state of cognition for the technology and have not risen to the real application practice.

They widespread have no interest in learning. Higher vocational students are easily to produce cognitive deviations. They only pay attention to the improvement of hands-on ability and do not pay attention to the development trend of manufacturing technology, which leads to the students' rejection of this kind of curriculum that covers a large number of theoretical knowledge and causes the loss of initiative and enthusiasm for learning.

\section{Design of Teaching Methods}

In view of the problems existing in the present teaching process, the main line is to arouse the students' initiative of learning, and the improvement is made from the aspects of teaching content, teaching mode, teaching means, assessment and evaluation methods.

Teaching content. During preparing lessons, teachers should know more about the latest development and frontier knowledge of advanced manufacturing technology through an extensive literature review and collect new novel case materials[2]. The knowledge points that have changed in the textbook should be updated in time to ensure that the course content is forward-looking, and to analyze the characteristics and cognitive level of the specialized students and determine the difficulty of the teaching content so that students can better absorb the understanding. In the course of designing the teaching process, teachers can choose the teaching content according to the professional and learning basis of the subject. Some content can be selectively placed in the follow-up course teaching, and the practical content can be combined with the practice operation, then the knowledge can be verified through practice.

Strengthen the Combination of Theory and Practice. The teaching model is adopted by combining theory with practice[3]. After having theoretical knowledge, we can strengthen the students' understanding of the basic profession theoretical knowledge, stimulate their interest in learning and arouse their enthusiasm for learning by observing and carrying out experiments. After explaining the principle of a specific advanced manufacturing technology, teachers can take the students to visit practical site according to the teaching conditions, aiming at to let the students immerse on the scene or to do practical operation by themselves to enhance the perceptual knowledge. What's more the students can not only improve their interest in learning, but also promote understanding.

Guide students to learn actively. The "task driven" teaching method is that teachers put forward teaching requirements to students according to practical problems in order to complete the special task. The teachers hide the teaching content ingeniously in every task, so that the students have answers and methods to solve the problems all by themselves or under the guidance of the teachers before starting exercises. Under the guidance of the teachers, the students can accomplish the corresponding tasks through their own learning process. When finishing the task, they will also master new skills naturally[4]. This kind of teaching mode have a great number of advantages, such as helping to change the classroom center from the teacher to the students, stimulating the students' enthusiasm for learning, improving the frequency of interaction between teachers and students and enhancing the ability of the students to organize, communicate and cooperate with each other.

Using information teaching method. According to the characteristics of advanced manufacturing technology, the information technology is organically integrated into the course teaching to broke traditional teaching method and create colorful teaching environment. Depend on multimedia integration tools or web development tools, the course content is integrated and processed with multimedia interaction, which is transformed into a digital learning resource, 
creating a teaching situation and improving the students' interest in learning[5]. Besides, advanced equipment, network simulation technology, video and multimedia courseware can also be widely used to make the students obtain knowledge intuitively and vividly. The most important is that using network teaching resources, simulation experiments, virtual experiment and practice can broaden the students' knowledge level.

Reform the examination forms. The traditional examined form on advanced manufacturing technology courses is examinations. This assessment type is monotonous, focusing on the students' memory and formula application to the knowledge points, but the students' working attitude, cooperation consciousness and innovation ability can't be fully reflected in the evaluation results. Otherwise, breaking the traditional assessment mode and establishing a new evaluation and evaluation methods is needed. The new form should include the following aspects. On one hand, the proportion of ordinary grades should be increased mainly from the attendance rate of the students, the completion of discussion assignments under class, the discussion of class participation, and so on. On the other hand, the total number of paper should be considered. Students are required to read relevant literature autonomously, put forward their own ideas and verification on a certain problem to writing a compelling paper[6]. This way not only can train the ability of students to access information and extract useful information, but also truly reflect the comprehensiveness and practicality of this course.

Strengthening the construction of the teaching staff. The training of professional skills for teachers should be carried out, such as going to enterprise as a worker, and introducing workers with high practical experience and technicians, advanced technicians and skilled craftsmen as professional practice advisor to strengthen the construction of the practice team and promote the teaching level. Teachers are encouraged to follow the path of "production, learning and research", and establish an excellent team of practical teaching combined with the basic indicators of teacher performance appraisal[7].

\section{Teaching Process Design}

In the course of advanced manufacturing technology, the information teaching mode is used to enrich the teaching resources and to sort out the teaching content. According to the Bloom classification method, the main knowledge points of this course are listed. On the basis of the knowledge and cognition expression, the teaching goal of knowledge point has been described again and the knowledge point teaching scheme has been compiled[8]. All the teachers should play a leading role in teaching activities with students centered. First of all, the information teaching situations that meet students' characteristics and teaching needs should be designed. We should try our best to design the real situation as much as possible, so that we can not only stimulate students' interest in learning, but also improve their actual combat ability. Secondly, teachers should provide good information resources to determine the information resources required for the project, such as text information, related pictures, video cases and so on. Besides, the network, software and other related supporting facilities that need to be utilized should also be provided. After preparing these resources in advance, teachers will guide students to effectively utilize these resources, or do some guidance so as to successfully complete the task.

In the teaching activities, teachers should not only put forward questions, but also give students the necessary guidance and correction in the process of analyzing problems and solving problems. For example, teachers should guide students how to carry out inquiry activities in the learning process and point out what steps need to be followed in order to complete the task. Finally, teachers should evaluate and reflect on the performance of students in each process so that they can adjust the design at any time. What's more, rethink profoundly is important to make students adapt to the teaching method. Both of teachers and students take significant role so as to achieve the most ideal teaching effect. Especially for the core part of student activities, teachers should focus on the evaluation and reflection, and modify in time[9]. 


\section{Conclusion}

Advanced manufacturing technology is a specialized course for learning and understanding the latest knowledge of the manufacturing industry. It covers a wide range of subjects, including mechanical, electronic, material, and computer science. Combining the traditional teaching methods in the aspects of teaching content, including teaching mode, teaching means and assessment and evaluation to develop a learning centered improvement will help to benefit the teaching effect.

\section{References}

[1] X.B. Li. Discussion on Improving Teaching Quality of Advanced Manufacturing Technique[J]. Mechanical Management and Development, Vol. 25 (2010) No.1, p.168-169.

[2] G.W. Li, D.S. Dong, W.J. Huang. Exploration on Teaching Reform of "Advanced Manufacturing Technology" Oriented to "Excellence Program"[J]. China Electric Power Education, (2014) No.21, p.31-32.

[3] T. Wang. Study of Teaching on Advanced Manufacturing Technology[J]. Times Agricultural Machinery, Vol. 39 (2012) No.9, p.171-171.

[4] M.C. Zhao. Review on the Instruction Methods of Constructionism[J]. Studies in Foreign Education, (2002) No.9, p.15-19.

[5] Z.H. Wu. Application of Smart Phones in Classroom Teaching in Higher Vocational Colleges[J]. China New Telecommunications, Vol. 18 (2016) No.7, p.54-55.

[6] C. Liang. The Construction Study of College Informationization Teaching Mode under the Background of Big Data [J]. China Educational Technology, (2017) No.12, p.98-102.

[7] Y.K. Li. The Main Problems and Countermeasures of Practical Training in Higher Vocational Colleges in China [J]. Education Exploration, (2015) No.2, p.56-59.

[8] G.M. Yuan, R.G. Hou, X.M. Huang. Exploration of Information Teaching Mode of Advanced Manufacturing Technology [J]. Education and Teaching Forum, (2017) No.16, p.262-263.

[9] Z.F. Ma. Research on the Design Pattern of Information Teaching in Higher Vocational Education [J]. The Chinese Journal of ICT in Education, (2015) No.16, p.53-55. 